\title{
ANALISIS KEMAMPUAN SISWA DALAM MENYELESAIKAN SOAL MATEMATIKA TIPE HIGHER ORDER THINKING SKILL (HOTS) POKOK BAHASAN POLA BILANGAN PADA KELAS VIII A SMP NEGERI 1 SUNGGUMINASA
}

\author{
Restu Wirdayanti Ramli ${ }^{1}$ \\ Nurdin Arsyad ${ }^{2}$ \\ Ma'rup $^{3 *}$ \\ ${ }^{1,3}$ Universitas Muhammadiyah Makassar, Makassar, Indonesia \\ ${ }^{3}$ Universitas Negeri Makassar, Makassar, Indonesia \\ rstuwirdayant@gmail.com ${ }^{1}$ \\ bsbudin@yahoo.com ${ }^{2}$ \\ marupprodimtk@gmail.com $^{3 *}$
}

\begin{abstract}
Abstrak
Penelitian ini bertujuan untuk mengetahui deskripsi kemampuan siswa dalam menyelesaikan soal matematika tipe Higher Order Thinking Skill (HOTS) pokok bahasan Pola Bilangan pada kelas VIII A SMP Negeri 1 Sungguminasa. Jenis penelitian ini adalah penelitian deskriptif dengan menggunakan pendekatan kualitatif yang dirancang untuk mengetahui deskripsi kemampuan siswa dalam menyelesaikan soal matematika tipe Higher Order Thinking Skill (HOTS) pokok bahasan Pola Bilangan. Subjek yang dipilih pada penelitian ini berjumlah 3 siswa, teknik pemilihannya berdasarkan masingmasing 1 siswa dari kelompok siswa berkemampuan tinggi, 1 siswa dari kelompok berkemampuan sedang dan 1 siswa dari kelompok berkemampuan rendah. Pengelompokan siswa yaitu berdasarkan hasil tes soal tipe Higher Order Thinking Skill (HOTS) yang telah diselesaikan siswa, maka 3 subjek terpilih kemudian diwawancarai untuk mengetahui kemampuan siswa dalam menyelesaikan soal matematika tipe Higher Order Thinking Skill (HOTS) yang ditinjau dari tahapan pemecahan masalah langkah Polya.
\end{abstract}

Kata Kunci: Higher Order Thinking Skill, Langkah Polya, Pola Bilangan

Diterbitkan Oleh:

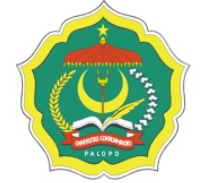

Fakultas Sains

Program Studi Matematika

Universitas Cokroaminoto Palopo

Copyright (C) 2021 The Author (s)

This article is licensed under CC BY 4.0 License

\section{(cc) BY}




\section{ANALISIS KEMAMPUAN SISWA DALAM MENYELESAIKAN SOAL MATEMATIKA TIPE HIGHER ORDER THINKING SKILL (HOTS) POKOK BAHASAN POLA BILANGAN PADA KELAS VIII A SMP NEGERI 1 SUNGGUMINASA}

\section{Pendahuluan}

Saat ini reformasi di dunia pendidikan sedang berlangsung di berbagai negara, termasuk di Indonesia. Perombakan terjadi pada sistem evaluasi yang mengarah pada anggapan bahwa pembelajaran yakni terkhusus pembelajaran matematika sepatutnya tidak sekadar berorientasi pada kemampuan matematis dan pengetahuan dasar, melainkan bisa lebih dipusatkan untuk mengembangkan kecakapan siswa dalam memecahkan masalah baru yang tidak rutin agar pembelajaran matematika bisa meraih totalitas dinamika proses berpikir siswa.

Reformasi yang terjadi diwarnai dengan diterapkannya pembelajaran serta evaluasi yang lebih berorientasi kepada Higher Order Thinking Skill (HOTS). Newman serta Wehlage (Hamidah, 2018), menyatakan bahwa HOTS dapat memberi peranan yang sangat besar dalam mendukung prestasi akademik siswa, dengan HOTS siswa mampu memecahkan masalah, menyeleksi ide ataupun pendapat, berhipotesis, berpendapat dengan bijak serta sanggup menguasai situasi yang lebih rumit.

Hal ini searah dengan pernyataan Thomas dan Thorne (Hamidah, 2018) yang menerangkan bahwa HOTS dapat diterapkan di dalam dunia pendidikan sehingga keterampilan dan karakter siswa dapat ditingkatkan. Dalam proses pembelajaran, terdapat perbedaan antara siswa yang lebih condong pada hafalan dengan siswa yang melatih keterampilan berpikir tingkat tingginya. Dengan menerapan pembelajaran tipe HOTS siswa tidak hanya sekadar hafal informasi melainkan juga melatih keterampilan berpikir tingkat tinggi yakni kemampuan siswa dalam menganalisis, mengevaluasi dan juga berkreasi. Karenanya itu, penting sekali untuk melatih kemampuaan berpikir tingkat tinggi siswa agar tidak sekadar mengingat tapi juga mampu mengimplementasikannya pada persoalan yang baru.

HOTS mulai diberlakukan dalam sistem evaluasi dan pembelajaran di kelas dengan harapan bahwa dengan HOTS kecakapan dan kreativitas berpikir siswa dapat lebih meningkat. Terhitung tahun 2017, soal HOTS sudah mulai disajikan saat ujian nasional dan kian bertambah pada UNBK tahun 2018 dan tahun-tahun berikutnya.

Tujuan terus diberlukannya HOTS yaitu untuk meningkatkan kemampuan berpikir siswa. Sikap tersebut mendapatkan respon yang baik di kalangan siswa dan juga tidak sedikit yang merespon buruk, banyak siswa yang mengeluh dikarenakan soal Matematika dalam UN 
tahun 2018 yang dianggap sangat sulit. Berdasarkan data yang diperoleh, nilai rata-rata siswa SMP mengalami penurunan pada UNBK tahun 2018, termasuk mata pelajaran matematika dan IPA. Nilai rata-rata siswa SMP pada tahun 2018 adalah 53,42 sementara itu di tahun sebelumnya tahun 2017 rata-rata nilai UNBK yaitu sebesar 56,27. Dari kedua data tersebut dapat dilihat bahwa dari tahun 2017 ke tahun 2018 nilai rata-rata siswa menurun sebanyak 2,85 dimana penurunan tersebut tidak terlalu besar dibandingkan dengan respon siswa yang lebih banyak kontra.

Dari beberapa informasi yang diperoleh oleh peneliti, SMP Negeri 1 Sungguminasa adalah sekolah negeri yang termasuk berprestasi di daerah Gowa. Selain itu SMP Negeri 1 sungguminasa juga telah melaksanakan peraturan pemerintah yaitu menerapkan kurikulum 2013. Akan tetapi sekolah tersebut belum menerapkan pembelajaran yang mengasah kemampuan berpikir tingkat tinggi yang seharunya dimiliki oleh siswa. Untuk itu perlu adanya penyajian data mengenai analisis kemampuan siswa dalam penyelesaian soal HOTS.

Berlandaskan hasil observasi awal peneliti, terdapat beberapa informasi yang didapati yaitu:

1. Dilihat dari nilai Ujian Tengah Semester (UTS), didapati siswa memiliki nilai yang beragam. Hal tersebut menunjukkan bahwa siswa juga memiliki kemampuan yang beragam dalam menyelesaikan soal.

2. Guru masih sangat terbatas dalam memberikan soal-soal matematika tipe HOTS kepada siswa dan lebih cenderung memberikan soal berkemampuan rendah (LOTS) dan soal berkemampuan sedang (MOTS).

Dari pemaparan beberapa masalah tersebut, penulis terdorong untuk melangsungkan penelitian yang berjudul “Analisis Kemampuan Siswa dalam Menyelesaikan Soal Matematika Tipe Higher Order Thinking Skills (HOTS) Pokok Bahasan Pola Bilangan pada Kelas VIII A SMP Negeri 1 Sungguminasa”. Penelitian ini penting dilakukan agar dapat diketahui sejauh mana kemampuan siswa menyelesaikan soal HOTS, dari informasi yang diperoleh tersebut bisa ditentukan langkah selanjutnya dalam peningkatan mutu siswa- siswi SMP Negeri 1 Sungguminasa.

Tujuan penelitian ini yakni untuk mengetahui deskripsi kemampuan siswa dalam menyelesaikan soal matematika tipe Higher Order Thinking Skill (HOTS) pokok bahasan pola bilangan siswa kelas VIII A SMP Negeri 1 Sungguminasa.

\section{Metode Penelitian}

Jenis penelitian yang digunakan dalam penelitian ini adalah penelitian deskriptif dengan 
pendekatan kualitatif. Penelitian ini dilakukan di SMP Negeri 1 Sungguminasa tepatnya di Jl. H. Habibu Kulle Nomor 25, Sungguminasa, Kecamatan Somba Opu, Kabupaten Gowa, Provinsi Sulawesi Selatan. Subjek pada penelitian ini adalah tiga siswa yang sesuai untuk penelitian yaitu masing-masing satu orang dari siswa kelompok berkemampuan tinggi, sedang dan rendah Dalam penelitian ini, pengambilan subjek yaitu menggunakan teknik purposive sampling dengan memperhatikan data yang diperoleh siswa pada saat diberikan tes lalu mengelompokkannya menjadi tiga kelompok. Instrumen dalam penelitian ini ialah peneliti sebagai instrumen utama, lembar soal tes Higher Order Thinking Skill (HOTS) dan pedoman wawancara. Pada penelitian ini digunakan teknik pengumpulan data yaitu tes tertulis dan wawancara. Teknik analisis data pada penelitian ini ialah hasil tes dan wawancara dianalisis secara deskriptif yang terdiri dari reduksi data, penyajian data dan kesimpulan. Untuk menguji keabsahan data, pada penelitian ini digunakan triangulasi teknik yaitu membandingkan hasil dari tes dengan hasil wawancara dari subjek.

\section{Hasil dan Pembahasan}

\subsection{Hasil}

Pelaksanaan proses penelitian diawali dengan tahap persiapan kemudian dilanjutkan ke tahap pengambilan data. Tahap persiapan dimulai sejak bulan September 2020 yaitu pengurusan surat ijin di sekolah serta penetapan kelas subjek. Selanjutnya pada tahap pengambilan data, diawali dengan pemberian soal tes tertulis secara daring melalui aplikasi Google Meet dan Classroom kemudian dilanjutkan dengan melakukan proses wawancara di hari berikutnya. Pada kegiatan penelitian, peneliti berniat mengambill sampel penelitian sebanyak 1 kelas yaitu beranggotakan 35 siswa, akan tetapi pada proses pelaksanaannya hanya dapat diikuti oleh 28 siswa yaitu 10 siswa laki-laki dan 18 siswa perempuan, sedangkan subjek yang terpilih untuk diwawancarai merupakan siswa yang memperoleh hasil tes tertinggi, sedang dan terendah. Adapun langkah-langkah penentuan subjek dalam peneltian ini adalah sebagaia berikut:

1. Mencari total skor siswa secara keseluruhan

2. Mencari Mean atau nilau rata-rata dan simpangan baku (SD). Dalam mencari nilai Mean diperoleh dengan cara berikut:

$$
\overline{\mathrm{x}}=\frac{\sum \mathrm{x}}{\mathrm{N}}
$$

Setelah diperoleh nilai rata-ratanya kemudian menghitung simpangan baku (SD) dengan cara berikut: 


$$
\mathrm{SD}=\sqrt{\frac{\sum \mathrm{x}^{2}}{\mathrm{~N}}-\left(\frac{\sum \mathrm{x}}{\mathrm{N}}\right)^{2}}
$$

3. Menetukan batas kelompok

Dari hasil yang diperoleh dari langkah 1 dan 2. Kemudian batas tingkat kemampuan siswa dapat ditentukan seperti berikut (Lihat Tabel 1):

Tabel 1. Kriteria Pengelompokan Subjek

\begin{tabular}{ccc}
\hline No & Interval & Tingkat Kemampuan Siswa \\
\hline 1 & Skor $\geq$ Mean + SD & Tinggi \\
2 & Mean-SD $\leq$ Skor $<$ Mean + SD & Sedang \\
3 & Skor $<$ Mean-SD & Rendah \\
\hline
\end{tabular}

Sumber: Arikunto (2012)

Dari data tersebut telah dikalkulasikan persentasi banyaknya siswa di setiap kelompok yaitu terdapat 5 orang atau sebanyak $17,85 \%$ siswa berkemampuan tinggi, 17 orang atau sebanyak $60,71 \%$ siswa berkemampuan sedang dan 6 orang atau 21,42\% siswa berkemampuan rendah. Adapun siswa yang terpilih sebagai subjek penelitian dapat dilihat pada Tabel 2 berikut:

Tabel 2. Pengkodean Subjek Terpilih

\begin{tabular}{ccrc}
\hline Inisial Subjek & Kode Subjek & Skor & Tingkat Kemampuan Siswa \\
\hline N.I. L & S-21 & 92 & Tinggi \\
N.M. A & S-18 & 73 & Sedang \\
C.D. P & S-05 & 46 & Rendah \\
\hline
\end{tabular}

Berikut adalah hasil tes kemampuan penyelesaian soal matematika tipe Higher Order Thinking Skill (HOTS) (Lihat Tabel 3):

Tabel 3. Hasil Tes Kemampuan Penyelesaian Soal Tes pada Subjek Ditinjau Berdasarkan Langkah Polya

\begin{tabular}{|c|c|c|c|c|c|}
\hline \multirow{2}{*}{$\begin{array}{l}\text { Kelompok } \\
\text { Siswa } \\
\text { Berdasarkan } \\
\text { Tingkat } \\
\text { Kemampuan } \\
\text { Siswa }\end{array}$} & \multirow{2}{*}{$\begin{array}{l}\text { Kode } \\
\text { Subjek }\end{array}$} & & \multicolumn{3}{|c|}{ Level Kognitif Soal HOTS } \\
\hline & & $\begin{array}{l}\text { ap } \\
\text { han } \\
\text { Polya }\end{array}$ & $\begin{array}{c}\mathrm{C} 4, \\
\text { Analyze } \\
\text { (menganalisis) }\end{array}$ & $\begin{array}{c}\text { C5 } \\
\text { Evaluate } \\
\text { (mengevalusi) }\end{array}$ & $\begin{array}{c}\text { C6, } \\
\text { Create } \\
\text { (mencipta) }\end{array}$ \\
\hline \multirow{5}{*}{ Tinggi } & \multirow{5}{*}{ S-21 } & 1 & $\sqrt{ }$ & $\sqrt{ }$ & $\sqrt{ }$ \\
\hline & & 2 & $\sqrt{ }$ & $\sqrt{ }$ & $\sqrt{ }$ \\
\hline & & 3 & $\sqrt{ }$ & $\sqrt{ }$ & $\sqrt{ }$ \\
\hline & & 4 & $\sqrt{ }$ & $\sqrt{ }$ & $\sqrt{ }$ \\
\hline & & 1 & $\sqrt{ }$ & $\sqrt{ }$ & $\sqrt{ }$ \\
\hline \multirow{2}{*}{ Sedang } & \multirow{2}{*}{ S-18 } & 2 & $\sqrt{ }$ & $\sqrt{ }$ & - \\
\hline & & 3 & $\sqrt{ }$ & - & - \\
\hline
\end{tabular}




\begin{tabular}{|c|c|c|c|c|c|}
\hline \multirow{2}{*}{$\begin{array}{l}\text { Kelompok } \\
\text { Siswa } \\
\text { Berdasarkan } \\
\text { Tingkat } \\
\text { Kemampuan } \\
\text { Siswa }\end{array}$} & \multirow{2}{*}{$\begin{array}{l}\text { Kode } \\
\text { Subjek }\end{array}$} & & \multicolumn{3}{|c|}{ Level Kognitif Soal HOTS } \\
\hline & & $\begin{array}{l}\text { ap } \\
\text { ahan } \\
\text { Polya }\end{array}$ & $\begin{array}{c}\mathrm{C} 4, \\
\text { Analyze } \\
\text { (menganalisis) }\end{array}$ & $\begin{array}{c}\mathrm{C} 5 \\
\text { Evaluate } \\
\text { (mengevalusi) }\end{array}$ & $\begin{array}{c}\text { C6, } \\
\text { Create } \\
\text { (mencipta) }\end{array}$ \\
\hline \multirow{5}{*}{ Rendah } & & 4 & $\sqrt{ }$ & - & - \\
\hline & & 1 & $\sqrt{ }$ & - & - \\
\hline & \multirow{3}{*}{ S-05 } & 2 & $\sqrt{ }$ & - & - \\
\hline & & 3 & $\sqrt{ }$ & - & - \\
\hline & & 4 & $\sqrt{ }$ & - & - \\
\hline
\end{tabular}

Keterangan:

$\sqrt{ }=$ Mampu dalam tahapan $\quad$ - = Tidak mampu dalam tahapan

1. Kemampuan penyelesaian soal tipe Higher Order Thinking Skill (HOTS) siswa S-21

Berdasarkan dari hasil tes dan hasil wawancara, peneliti dapat menyimpulkan bahwa subjek S-21 menyelesaikan soal HOTS dengan baik dan benar baik pada indikator analyze (menganalisis), evaluate (mengevaluasi), dan create (mencipta) dengan melaksanakan semua tahapan pemecahan masalah.

2. Kemampuan penyelesaian soal tipe Higher Order Thinking Skill (HOTS) siswa S-18 Berdasarkan dari hasil tes dan hasil wawancara, peneliti dapat menyimpulkan bahwa subjek S-18 menyelesaikan soal HOTS dengan baik dan benar pada indikator analyze (menganalisis) dengan melaksanakan semua tahapan pemecahan masalah. Namun pada indikator evaluate (mengevaluasi) hanya melaksanakan separuh tahapan pemecahan masalah dan pada indikator create (mencipta) hanya melaksanakan satu tahapan pemecahan masalah.

3. Kemampuan penyelesaian soal tipe Higher Order Thinking Skill (HOTS) siswa S-05 Berdasarkan dari hasil tes dan hasil wawancara, peneliti dapat menyimpulkan bahwa subjek S-05 menyelesaikan soal HOTS dengan baik dan benar pada indikator analyze (menganalisis) dengan melaksanakan semua tahapan pemecahan masalah. Namun pada indikator evaluate (mengevaluasi) dan create (mencipta) subjek S-05 sama sekali tidak melaksanakan semua tahapan pemecahan masalah. 


\subsection{Pembahasan}

1. Analisis kemampuan penyelesaian soal tipe Higher Order Thinking Skill (HOTS) siswa S-21

Berdasarkan dari hasil analisis data yang telah dipaparkan sebelumnya siswa berkemampuan tinggi yaitu S-21 berada pada tingkat "mampu" baik pada soal HOTS indikator analyze (menganalisis), evaluate (mengevaluasi) maupun create (mencipta) karena mampu menyelesaikan soal-soal dengan baik dan benar dengan melaksanakan semua tahapan pemecahan masalah.

2. Analisis kemampuan penyelesaian soal tipe Higher Order Thinking Skill (HOTS) siswa S-18

Berdasarkan dari hasil analisis data yang telah dipaparkan sebelumnya siswa berkemampuan sedang yaitu S-18 berada pada tingkat "mampu" pada indikator analyze (menganalisis) karena mampu menyelesaikan soal dengan baik dan benar dengan melaksanakan semua tahapan pemecahan masalah, sedangkan pada indikator evaluate (mengevaluasi) dan create (mencipta) S-18 berada pada tingkat "kurang mampu" karena tidak mampu menyelesaikan soal dengan baik dan benar dengan hanya melaksanakan beberapa tahapan pemecahan masalah

3. Analisis kemampuan penyelesaian soal tipe Higher Order Thinking Skill (HOTS) siswa S-05

Berdasarkan dari hasil analisis data yang telah dipaparkan sebelumnya siswa berkemampuan sedang yaitu S-05 berada pada tingkat "mampu" pada indikator analyze (menganalisis) karena mampu menyelesaikan soal dengan baik dan benar dengan melaksanakan semua tahapan pemecahan masalah, sedangkan pada indikator evaluate (mengevaluasi) dan create (mencipta) S-05 berada pada tingkat "tidak mampu" karena tidak mampu menyelesaikan soal dengan baik dan benar dengan sama sekali tidak melaksanakan semua tahapan pemecahan masalah.

\section{Kesimpulan}

Berlandaskan hasil dari penelitian maupun pembahasan, adapun kesimpulan penelitian ini ialah kemampuan siswa menyelesaikan soal HOTS yang diteliti dengan pemberian tes menunjukkan dari total sebanyak 28 orang siswa terdapat 17,85\% atau sebanyak 5 siswa yang tergolong dalam kelompok berkemampuan tinggi, 60,71\% atau sebanyak 17 siswa yan tergolong dalam kelompok berkemampuan sedang, dan 21,42\% atau 6 siswa yang tergolong dalam kelompok berkemampuan rendah. Berdasarkan tingkat persentasi tersebut dapat ditarik 
sebuah kesimpulan bahwa kemampuan siswa kelas VIII A SMP Negeri 1 Sungguminasa dalam menyelesaiakan soal tipe HOTS termasuk baik, hal itu ditunjukkan dengan tingkat persentasi siswa berkemampuan rendah yang terhitung lebih minim dibandingkan persentasi siswa berkemampuan sedang dan siswa berkemampuan tinggi. Siswa berkemampuan tinggi berada pada tingkat "mampu" baik pada indikator analyze (menganalisis), evaluate (mengevaluasi) maupun create (mencipta). Sedangkan siswa yang berkemampuan sedang dan rendah masih berada pada tingkat yang "kurang mampu" khususnya pada indikator evaluate (mengevaluasi) maupun create (mencipta).

\section{DAFTAR PUSTAKA}

Abidin, 2014. Desain Sistem Pembelajaran dalam Konteks Kurikulum. 2013. Bandung: PT Refika aditama.

Abosalem, Yousef. 2016. Assessment Techniques and Students Higher-Order Thinking Skills. International Journal of Secondary Education, Vol: 4, No: 1, p: 1-11.

Agasi, G. R. 2014. Profil kemampuan siswa SMP Beferi 6 Yogyakarta Kelas VIII B Tahun Ajaran 2013/2014 Dalam Menyelesaikan Soal TIMSS. Yogyakarta: Universitas Sanata Dharma.

Arikunto, Suharsimi. 2010. Prosedur Penelitian. Jakarta: Rineka Cipta.

Arimbi, Amy. 2017. Pola Bilangan, Barisan dan Deret. Tersedia di https://www.slideshare.net/Amyarimbi/bahan-ajar-pola-bilangan-barisan-dan-deret [diakses 13-11-2019]

Hamidah, Luluk. 2018. Higher Order Thinking Skills (Seni Melatih Kemampuan Berpikir Tingkat Tinggi. Yogyakarta: Hijaz Pustaka Mandiri.

Hamzah, A. dan Muhlisrarini. 2014. Perencanaan dan Stategi Pembelajaran Matematika. Jakarta: PT Raja Grafindo Persada

Hassan, S. R., Rosli, R., \& Zakaria, E. (2016). The Use of i-Think Map and Questioning to Promote Higher-Order Thinking Skills in Mathematics. Creative Education, 7, 10691078.doi:http://dx.doi.org/10.4236/ce.2016.77111

Hasyim, M., \& Andreina, F. K. (2019). Analisis high order thinking skill (hots) siswa dalam menyelesaikan soal open ended matematika. FIBONACCI: Jurnal Pendidikan Matematika dan Matematika, 5(1), 55-64.

KBBI, 2016. Kamus Besar Bahasa Indonesia (KBBI). [Online] Available at: http://kbbi.web.id/pusat, [Diakses 29-07-2019].

Kemendikbud. 2017. Modul Penyusunan Soal Higher Order Thinking Skill (HOTS). Dirjen 
Pendidikan Dasar dan Menengah.

Komalasari, Kokom. 2013. Pembelajaran Kontekstual Konsep dan Aplikasi. Bandung: PT Refika Aditama

Moleong, Lexy J. 2014. Metodologi Penelitian Kualitatif. Bandung: Remaja Rosdakarya

Muncarno, 2008. "Penerapan Model Penyelsaian Soal erita dengan Langkah-Langkah Pemecahan Masala untuk Meningkatkan Prestasi Belajar Matematika Siswa Kelas 1 SMP”. Jurnal Nuansa Pendidikan. Lampung: LPMP Universitas Lampung.

Permendikbud Nomor 20 Tahun 2016 tentang Standar Kompetensi Lulusan Pendidikan Dasar Dan Menengah.

Prastowo, A. 2016. Metode Penelitian Kualitatif dalam Perspektif Rancangan Penelitian. Yogyakarta: AR-Ruz Media.

Retnawati Heri, ed. 2018. Desain Pembelajaran Matematika untuk Melatihkan Higher Order Thinking Skill. Yogyakarta : UNY PRESS.

Riyana, C. 2017. Komponen-Komponen Pembelajaran. Tersedia di http://file.upi.edu/Direktori/FIP/JUR.PEND._LUAR_BIASA/196209061986011AHMA D MULYADIPRANA/PDF/Komponen_Pembelajaran.pdf [diakses 29-07-2020]

Sugiyono. 2011. Metode Penelitian Pendidikan (Pendekatan Kuantitatif, Kualitatif dan R\&D). Bandung: Alfabeta

Suryapuspitarini, B. K. 2018. Analisis Soal-soal Matematika Tipe Higher Order Thinking Skill (HOTS) pada Kurikulum 2013 untuk Mendukung Kemampuan Literasi Siswa. PRISMA. Prosiding Seminar Nasional Matematika. Vol 1, No 1

Wardhani, Sri. 2010. Implikasi Karakteristik Matematika dalam Penacapaian Tujuan Mata Pelajaran Matematika di SMP/MTs. Yogyakarta: PPPPTK

Widana, Wayan. 2017. Modul Penyusunan Soal Higher Order Thinking Skill. Jakarta: Departemen Pendidikan dan Kebudayaan. 